\title{
Comment on: A commentary on changing infant death rates and a plea to use sudden infant death syndrome as a cause of death
}

\author{
David T. Mage
}

Accepted: 6 July 2012/ Published online: 3 August 2012

(C) Springer Science+Business Media, LLC 2013

Krous [1] recently published "a plea to use sudden infant death syndrome as a cause of death" instead of a cause of death related to asphyxial risk factors that are non-fatal per se. It is interesting to note that Gilbert-Barness and Barness [2] published an invited editorial in 1993 that made a completely opposite plea. They reasoned that SIDS is not a cause of death, but rather a term for a death of unknown cause, and concluded as follows:

We make a plea that the term SIDS [Sudden Infant Death Syndrome] be abandoned and the diagnosis sudden infant death be substituted, with the qualifications implicit in each case. It is only by so doing that we will identify the causes of sudden infant death. [2]

To resolve these apparent diametrically opposed points of view, it is suggested that the World Health Organization's (WHO) 10th International Classification of Diseases for SIDS of R95 be modified. WHO has already added new codes R95.0 for SIDS with mention of autopsy and R95.9 for SIDS without mention of autopsy for implementation in January 2013 [3]. Perhaps codes such as R95.1, R95.2, and
R95.3 could be added for autopsied sudden infant deaths in supine, prone, and side final sleeping positions, respectfully, R95.4 could be used for other circumstances (e.g. in a car seat) and R95.0 could then be used when autopsied, but final sleep position was unknown or not mentioned.

In summary, it is proposed that such a distinction within 10ICD R95 would answer both the pleas of Dr. Krous and Drs. Barness, by distinguishing those cases where a change of sleep position from prone to supine could have possibly saved the infant from the sudden death.

\section{References}

1. Krous HF. A commentary on changing infant death rates and a plea to use sudden infant death syndrome as a cause of death. Forensic Sci Med Pathol. 2012. doi:10.1007/s12024-012-9354-x.

2. Gilbert-Barness EF, Barness LA. Sudden infant death syndromeis it a cause of death? Arch Pathol Lab Med. 1993;117:1246-8.

3. World Health Organization. http://www.who.int/classifications/icd/ ICD-10Updates2009.pdf. Accessed 25 June 2012.
D. T. Mage $(\bowtie)$

World Health Organization (retired), 18 W. Periwinkle Lane,

Newark, DE 19711-6212, USA

e-mail: magedonner@aol.com 